\title{
SOCIO-DEMOGRAPHIC CHARACTERISTICS AND TREATMENT OUTCOME OF PATIENTS WITH MALIGNANCY AND TYPE 2 DIABETES
}

\author{
MD. RAZIUR RAHMAN ${ }^{1}$, SAMIRA RAHAT AFROZE ${ }^{2}$, RENE SUZAN CLAUDE SARKER ${ }^{3}$, MUHAMMAD ABDUR \\ RAHIM $^{4}$ KHWAJA NAZIM UDDIN ${ }^{5}$
}

\begin{abstract}
Background: In Bangladesh prevalence of malignancy in diabetic patients seems to be increasing as case detection of both diseases are far more than before. No statistical data of diabetic patients with malignancy is currently available in Bangladesh. Treatment of both diabetes and malignancy in the same patient is challenging for the physician and requires multidisciplinary support. For such cases BIRDEM General Hospital offers supportive facilities including intensive care, chemotherapy, surgical intervention and oncology day care.

Methods : This is a cross-sectional observational study carried out from January 2011 to June 2016 which included adult diabetic patients with malignancy admitted in Internal Medicine Department of BIRDEM General Hospital. With prior informed consent of the patients, data were collected and statistical analysis was done using professional SPSS version 17.0 windows based program.

Results : Total number of type 2 diabetic patients with malignancy was 80. Among them 49 (61.3\%) were male and 31 (37.7\%) were female patients. Almost two-third of the patients was between 41-60 years (63.8\%). More than half of the patients belonged to urban settings (42, $52.5 \%)$ followed by sub-urban area $(27,33.7 \%)$. Smoking was the commonest $(23.8 \%)$ among the risk factors. Family history for malignancy and exposure to occupational hazards were present in $11.3 \%$ and $7.5 \%$ cases respectively. Among co-morbid conditions, hypertension and ischemic heart disease were predominant. Twenty categories of malignancies were confirmed by histopathological evidence, radiology reports and cancer markers. The commonest malignancy in male and female was lymphoma and carcinoma breast respectively. Most patients were treated with chemotherapy $(48.8 \%)$ and combined approach was required in $36.3 \%$ cases. Good response to treatment was observed in $46.3 \%$ cases, $15 \%$ patients deteriorated and death occurred in $6.3 \%$ cases.

Conclusion : Type 2 diabetes and malignancy individually have their own consequences. When co-existing, patients require a holistic approach. Complications can arise from either spectrum of the diseases. If managed promptly and adequately, outcome of such cases is encouraging. Management outcome of these cases so far in Internal Medicine Department, BIRDEM General Hospital shows a promising future.
\end{abstract}

Keywords : type 2 diabetes, malignancy, outcome, socio-demographics

Received: 03 January 2016

Accepted: 28 May 2017

\section{Introduction:}

Cancer prevalence in diabetic patients in our country seems to be increasing as case detection of both diseases are far more than before. Worldwide, cancer is the second and diabetes is the $12^{\text {th }}$ leading cause of death. ${ }^{1}$ Statistical data of diabetic patients with cancer is currently not available in Bangladesh.
Treatment of diabetes and malignancy in the same patient poses a challenge for the concerning physician. Due to limited advanced treatment facilities in Bangladesh, a patient with both cancer and uncontrolled diabetes often suffers.

Bangladesh Institute of Research and Rehabilitation in Diabetes, Endocrine and Metabolic Disorders

1. Associate Professor, Department of Internal Medicine, BIRDEM General Hospital \& Ibrahim Medical College.

2. Registrar, Department of Internal Medicine, BIRDEM General Hospital\& Ibrahim Medical College.

3. Senior Medical Officer, Department of Internal Medicine, BIRDEM General Hospital.

4. Assistant Professor, Nephrology Department, BIRDEM General Hospital.

5. Professor, Department of Internal Medicine, BIRDEM General Hospital \& Ibrahim Medical College.

Address of Correspondence: Dr. Md. Raziur Rahman, MD (Medicine), Associate Professor, Internal Medicine, BIRDEM General Hospital. E-mail: raziur@hotmail.com

Bangladesh J Medicine 2017; $28: 70-74$ 
(BIRDEM) General Hospital is well recognized for its service mostly to diabetic patients with multiple complications. Oncology unit of Internal Medicine Department of this hospital has started treating diabetic patients with malignancies with limited resources and facilities. For such cases our hospital also offers supportive facilities including intensive care, chemotherapy, surgical intervention and oncology day care.

The aim of this study was to observe the social and demographic characteristics in type 2 diabetic patients diagnosed with malignancy. The treatment outcomes of different categories of malignancy among these patients were also observed.

\section{Methodology:}

This cross-sectional, observational study was carried out from January 2011 to June 2016 in Oncology unit, Internal Medicine Department of BIRDEM General Hospital. Adult type 2 diabetic patients of either sex diagnosed with malignancy were purposively and

consecutively included in this study. With prior informed consent of the patients, data were collected and statistical analysis was done using professional SPSS version 17.0 windows based program. Sociodemographic characteristics, risk factors for malignancy such as smoking, alcohol intake, family history of malignancy and exposure to occupational hazards were evaluated in this study and treatment outcome of these patients were noted. Good response was categorized by improvement of both clinical and biochemical parameters including monitoring of cancer markers. Patients who had no relapse in 5 years were considered as cured. Cases were categorized as deteriorated if the patient's condition worsened following admission before or after receiving treatment. As radiotherapy facilities are not yet available at our hospital, 2 patients had to receive radiotherapy from an outside center. Cases were followed up after discharge for a variable period of time or till death. Patients who expired during hospitalization or after discharge were also noted.

\section{Results:}

Total number of type 2 diabetic patients with malignancy was 80 , whose diagnoses were confirmed by histo-pathological evidence (biopsy/FNAC), radiology reports and cancer markers. Among them $49(61.3 \%)$ were male and $31(37.7 \%)$ were female patients (Table 1). Almost two-third of the patients age was between 41-60 years $(51,63.8 \%)$. Others were above $>60$ years $(22,27.5 \%)$ and among $20-40$ years group $(7,8.7 \%)$. Mean age was $55.16 \pm 9.18$ SD years. Majority of the patients belonged to urban settings
(42, $52.5 \%)$ followed by sub-urban area $(27,33.7 \%)$ Most male patients came from urban settings (20, $64.5 \%)$ while most females $(12,60 \%)$ came from suburban settings.

\section{Table-I}

Distribution of gender, age and area of residence among diabetic patients with malignancy

\begin{tabular}{llcccc}
\hline Area of & Gender & \multicolumn{3}{c}{ Age group } & \multicolumn{2}{c}{ Total } \\
\cline { 3 - 5 } residence & & $20-40$ & $41-60$ & $>60$ & \\
\hline Urban & Male & 3 & 20 & 9 & 32 \\
& Female & 4 & 5 & 1 & 10 \\
& Total & 7 & 25 & 10 & 42 \\
Rural & Male & 0 & 4 & 0 & 4 \\
& Female & 0 & 3 & 4 & 7 \\
& Total & 0 & 7 & 4 & 11 \\
Sub-urban & Male & 0 & 7 & 6 & 13 \\
& Female & 0 & 12 & 2 & 14 \\
& Total & 0 & 19 & 8 & 27 \\
\hline
\end{tabular}

Risk factors for malignancy such as smoking, alcohol intake, family history of malignancy and exposure to occupational hazards were evaluated in this study. Among the 80 patients, $19(23.8 \%)$ were smokers and all were male (Table II). Of these 19 patients with smoking habit, most belonged to urban setting (11, $57.9 \%)$. The rest were from sub-urban and rural settings and showed equal number of smoking habit $(4,21 \%)$.

Table-II

Smoking prevalence with relation to sex and area of residence

\begin{tabular}{llccc}
\hline \multirow{2}{*}{$\begin{array}{l}\text { Area of } \\
\text { residence }\end{array}$} & Gender & \multicolumn{2}{c}{ Smoker } & Total \\
\cline { 3 - 4 } & & No & Yes & \\
\hline Urban & Male & 21 & 11 & 32 \\
& Female & 10 & 0 & 10 \\
\multirow{5}{*}{ Rural } & Total & 31 & 11 & 42 \\
& Male & 0 & 4 & 4 \\
\multirow{5}{*}{ Sub-urban } & Female & 7 & 0 & 7 \\
& Total & 7 & 4 & 11 \\
& Male & 9 & 4 & 13 \\
& Female & 14 & 0 & 14 \\
& Total & 23 & 4 & 27 \\
\hline
\end{tabular}

History of alcohol intake were found in 2 patients $(2.5 \%)$ only and both were male from urban settings (Table III). Nine patients (11.3\%) had positive family history for malignancy, 5 belonging to sub-urban settings and 4 from urban settings (Table IV). 
Table III

Prevalence of alcohol intake with relation to sex and area of residence

\begin{tabular}{|c|c|c|c|c|}
\hline \multirow{2}{*}{$\begin{array}{l}\text { History of } \\
\text { alcohol } \\
\text { intake }\end{array}$} & \multirow{2}{*}{$\begin{array}{l}\text { Area of } \\
\text { residence }\end{array}$} & \multicolumn{2}{|c|}{ Gender } & \multirow[t]{2}{*}{ Total } \\
\hline & & $\overline{\text { Male }}$ & $\overline{\text { Female }}$ & \\
\hline \multirow[t]{4}{*}{$\mathrm{No}$} & Urban & 30 & 10 & 40 \\
\hline & Rural & 4 & 7 & 11 \\
\hline & Sub-urban & 13 & 14 & 27 \\
\hline & Total & 47 & 31 & 78 \\
\hline \multirow[t]{2}{*}{ Yes } & Urban & 2 & 0 & 2 \\
\hline & Total & 2 & 0 & 2 \\
\hline
\end{tabular}

Table IV

Family history of malignancy

\begin{tabular}{lcccc}
\hline & \multicolumn{3}{c}{ Area of residence } & Total \\
\cline { 2 - 4 } $\begin{array}{l}\text { Family history } \\
\text { of malignancy }\end{array}$ & Urban & Rural & $\begin{array}{c}\text { Sub- } \\
\text { urban }\end{array}$ & \\
\hline No & 38 & 11 & 22 & 71 \\
Yes & 4 & 0 & 5 & 9 \\
\hline Total & 42 & 11 & 27 & 80 \\
\hline
\end{tabular}

Exposure to occupational hazards (such as working with chemicals in factories or radiation exposure) among diabetic patients with malignancy were observed in $6(7.5 \%)$ patients. Most of them (4) were male and from urban residential area, while one was female (Table V). Among co-morbid conditions (Table VI), hypertension (HTN) and ischemic heart disease (IHD) were predominant (15 and 9 cases respectively). Prevalence of more than one co-morbidites were marked (33 cases, 41.3\%) while 21 (26.3\%) patients had no co-morbidities. Patients with one or more comorbidities were mostly from urban settings (42, $52.5 \%)$.

Table V

Exposure to occupational hazards among diabetic patients with malignancy

\begin{tabular}{llccc}
\hline \multirow{2}{*}{$\begin{array}{l}\text { Exposure to } \\
\text { occupational } \\
\text { hazards }\end{array}$} & $\begin{array}{l}\text { Area of } \\
\text { residence }\end{array}$ & \multicolumn{2}{c}{ Gender } & Total \\
\cline { 3 - 4 } & & Male & Female & \\
\hline Not- & Urban & 28 & 9 & 37 \\
significant & Rural & 4 & 7 & 11 \\
& Sub-urban & 12 & 14 & 26 \\
& Total & 44 & 30 & 74 \\
Significant & Urban & 4 & 1 & 5 \\
exposure & Sub-urban & 1 & 0 & 1 \\
\hline & Total & 5 & 1 & 6 \\
\hline
\end{tabular}

Table VI

Co-morbid conditions in admitted type 2 patients with malignancy

\begin{tabular}{lcccc}
\hline \multirow{2}{*}{$\begin{array}{l}\text { Co-morbid } \\
\text { conditions }\end{array}$} & \multicolumn{3}{c}{ Area of residence } & Total \\
\cline { 2 - 4 } & Urban & Rural & Sub-urban & \\
\hline None & 15 & 2 & 4 & 21 \\
HTN & 7 & 4 & 4 & 15 \\
IHD & 5 & 0 & 4 & 9 \\
Liver disease & 2 & 0 & 0 & 2 \\
More than one & 13 & 5 & 15 & 33 \\
\hline Total & 42 & 11 & 27 & 80 \\
\hline
\end{tabular}

Twenty categories of malignancies were diagnosed during this study period (Table VII). Nearly half of cases were lymphoma $(16,20 \%)$, carcinoma breast $(11,13.8 \%)$, and carcinoma uterus and/or cervix (9, $11.3 \%)$. Most diabetic patients with diagnosed malignancies were from urban residential area (42, $52.5 \%)$. In males the common malignancies were lymphoma (15) and carcinoma pancreas (4) followed by carcinoma stomach (3), multiple metastasis (3), renal cell carcinoma (3) and carcinoma of lung (2). All cases of multiple myeloma (4), leukemia (5), hepatocellular carcinoma (2), renal cell carcinoma (3), carcinoma urinary bladder (2), carcinoma esophagus (1) and CNS malignancy (1) occurred in male patients. Among the female patients the common malignancies were carcinoma breast and carcinoma of uterus and/ or cervix. Cases of carcinoma of salivary gland (1), gall bladder (1), spinal cord (1) and carcinoma of unknown primary (1) occurred in female patients.

Table VII

Oncological diagnosis of admitted type 2 diabetic patients

\begin{tabular}{|c|c|c|c|c|}
\hline \multirow{2}{*}{$\begin{array}{l}\text { Oncological } \\
\text { Diagnosis }\end{array}$} & \multicolumn{3}{|c|}{ Area of residence } & \multirow[t]{2}{*}{ Total } \\
\hline & $\overline{\text { Urban }}$ & Rural & $\overline{\text { Sub-urban }}$ & \\
\hline Lymphoma & 9 & 3 & 4 & 16 \\
\hline Ca Breast & 6 & 0 & 5 & 11 \\
\hline Ca lung & 1 & 1 & 1 & 3 \\
\hline Ca Stomach & 3 & 1 & 0 & 4 \\
\hline Ca uterus \& cervix & 0 & 2 & 7 & 9 \\
\hline Multiple myeloma & 3 & 1 & 0 & 4 \\
\hline Ca pancreas & 4 & 1 & 0 & 5 \\
\hline Leukemia & 2 & 0 & 3 & 5 \\
\hline Salivary gland $\mathrm{Ca}$ & 0 & 0 & 1 & 1 \\
\hline Ca rectum & 1 & 1 & 0 & 2 \\
\hline Multiple metastasis & 5 & 0 & 0 & 5 \\
\hline Prostatic $\mathrm{Ca}$ & 1 & 0 & 1 & 2 \\
\hline Hepatic $\mathrm{Ca}$ & 2 & 0 & 0 & 2 \\
\hline Ca Gall bladder & 0 & 1 & 0 & 1 \\
\hline Renal cell $\mathrm{Ca}$ & 2 & 0 & 1 & 3 \\
\hline Ca urinary bladder & 1 & 0 & 1 & 2 \\
\hline${ }^{*} \mathrm{CNS} \mathrm{Ca}$ & 0 & 0 & 1 & 1 \\
\hline Ca spinal cord & 0 & 0 & 1 & 1 \\
\hline $\mathrm{Ca}$ esophagus & 0 & 0 & 1 & 1 \\
\hline Primary unknown & 2 & 0 & 0 & 2 \\
\hline Total & 42 & 11 & 27 & 80 \\
\hline
\end{tabular}

Ca : carcinoma, ${ }^{*} \mathrm{CNS}$ : central nervous system 
Case confirmation mostly was done by tissue diagnosis by histopathology following biopsy $(58,72.5$ $\%)$ and FNAC (17, $21.3 \%)$. In 5 cases diagnosis was made with the help of tumor marker, imaging and cytology (Table VIII).

Table VIII

Diagnostic tools used

\begin{tabular}{lc}
\hline Investigations & Number \\
\hline${ }^{*}$ FNAC & 17 \\
**Biopsy & 58 \\
Tumor marker & 1 \\
Cytology & 1 \\
Imaging & 3 \\
\hline Total & 80 \\
\hline
\end{tabular}

*FNAC : fine needle aspiration cytology

** Biopsy: includes bone marrow study, organ or lymph node biopsy, tissue biopsy (e.g. breast)

Most patients were treated with chemotherapy (39, $48.8 \%$ ). Many cases warranted a combined approach $(29,36.3 \%)$. Cases such as carcinoma breast, uterine and/or cervical cancers needed surgery and chemotherapy and / or radiotherapy. Surgical removal of tumor both curative and palliative surgery were required in 6 cases $(7.5 \%)$. The treatment modalities are shown in

Table IX. In all cases multidisciplinary approach were needed.

Table IX

Treatment modalities

\begin{tabular}{lc}
\hline Treatment modalities & Total \\
\hline None & 4 \\
Chemotherapy & 39 \\
Surgery & 6 \\
Palliative Radiotherapy & 2 \\
Combination & 29 \\
\hline Total & 80 \\
\hline
\end{tabular}

Treatment responses (Table X) among stable cases were satisfactory. Patients showed good response in $37(46.3 \%)$ cases. Four cases were declared 'cured' during this study period. In 12 patients $(15 \%)$ condition deteriorated. Death occurred in 5 cases $(6.3 \%)$ among whom 3 patients expired during hospitalization and 2 cases died after discharge. Ten cases $(12.5 \%)$ were lost to follow up in this study.
Table $\mathbf{X}$

Treatment outcomes of the patients

\begin{tabular}{lc}
\hline Outcome & Total \\
\hline No response & 12 \\
Good response & 37 \\
Cured & 4 \\
Deterioration & 12 \\
Death & 5 \\
Lost to follow-up & 10 \\
\hline Total & 80 \\
\hline
\end{tabular}

Discussion:

Diabetes may influence the neoplastic process by several mechanisms, including hyperinsulinemia (either endogenous due to insulin resistance or exogenous due to administered insulin or insulin secretogogues), hyperglycemia, or chronic inflammation. ${ }^{2}$ Our study was to share our experience in the field of oncology.

About $63.8 \%$ of study samples were within age limit of 41 to 60 years which almost correlates with Bangladesh Cancer Registry Report (30-65 years, around $66 \%) .^{3}$ Most diabetic patients with complications were of older age. Our study reflects that majority of the diabetic patients came from urban areas $(52.5 \%)$. The smaller group from rural areas $(11,13.75 \%)$ may be due to financial constrains or lack of opportunity to reach a tertiary care center.

There are some risk factors common to both cancer and diabetes which include age, sex, obesity, physical inactivity, diet, alcohol, and smoking. It has been recommended that healthful diets, physical activity and weight management reduce risk and improve outcomes of type 2 diabetes and some forms of cancer and should be promoted for all. ${ }^{2}$ In our study, 23.8\% were smokers and $2.5 \%$ were alcohol abusers. It was also observed that $11.3 \%$ had family history for malignancy and $7.5 \%$ patients were exposed to occupational hazards.

Diabetes-related factors including steatosis, nonalcoholic fatty liver disease and cirrhosis may also enhance susceptibility to liver cancer. With regard to pancreatic cancer, interpretation of the causal nature of the association is complicated by the fact that abnormal glucose metabolism may be a consequence of pancreatic cancer (so-called "reverse causality"). ${ }^{2}$ Epidemiological data have shown that diabetes (primarily type 2) is associated with up to two-fold increased risks of cancers of the colo-rectum, breast, endometrium, kidney (renal cell tumours), liver and 
pancreas among diabetes patients. ${ }^{2,4}$ Diabetes is associated with reduced risk of prostate cancer. ${ }^{2,5}$ For some other cancer sites there appears to be no association or the evidence is inconclusive. ${ }^{2}$

In our study among 20 catagories of malignancy majority suffered from lymphoma (both Hodgkins and non-Hodgkins lymphoma) carcinoma breast, carcinoma uterus and/or cervix.

In males common malignancies were lymphoma and carcinoma pancreas. Among the female patients the common malignancies were carcinoma breast and carcinoma of uterus and/or cervix. According to a large study on 6492 cancer patients conducted in National Institute of Cancer Research and Hospital of Bangladesh, the common cancers in adult males included cancers of lung, lymphatics, larynx, oral cavity and skin, while in adult females breast, cervix, lung, oral cavity, lymphatics and ovarian cancer were common ${ }^{6}$. Bangladesh Cancer Registry Report also mentions lung cancer as the most frequent cancer, followed by carcinoma cervix and breast. ${ }^{3}$

Confirmation of cases in this study was largely based on tissue diagnosis (72.5\%) from histopathology samples of bone marrow aspiration and organ biopsy. With the help of radiological evidence many cases were initially suspected as malignancy, which were later proven by histopathology, eventually a combined approach. Two cases of carcinoma of unknown primary with metastasis were also noted.

Two cases of carcinoma breast developed complication after chemotherapy and were referred to an outside center for radio/brachytherapy. Few patients with multiple metastasis were offered paliative care including surgery/stenting and chemotherapy. It has been emphasized that the best treatment for most of the complications of cancer is to successfully treat the cancer itself; if this is not feasible, palliative measures should be taken. ${ }^{7}$ Although treating the complications associated with cancer cannot always prolong the patient's life, it frequently can improve the quality of life remaining. ${ }^{7}$

In this study, we observed a significant combined data of 'cured' and 'patient with good response' (54.4\%). Death rate was $7 \%$ and condition deteriorated in $14 \%$ cases. Such outcomes can be expected in complicated diabetes with terminal illness ${ }^{8}$. Results of some, but not all, epidemiological studies suggest that diabetes may significantly increase mortality in patients with cancer. ${ }^{9}$ In one study, 5-year mortality rates were significantly higher (hazard ratio 1.39) in patients diagnosed with both breast cancer and diabetes than in comparable breast cancer patients without diabetes. ${ }^{10}$

\section{Conclusion:}

When a diabetic patient develops malignancy, the situation gets complicated. This group of patients at the same time need proper control of their glycaemic profile and specific management of carcinoma. Multidisciplinary management is often required. Complications can arise from either spectrum of the diseases. If managed promptly and adequately, outcome of such cases is encouraging. BIRDEM General Hospital as a tertiary institute shows a promising role here. Our oncology unit is looking forward to provide a better future to all patients who are fighting against cancer with diabetes mellitus.

\section{References:}

1. Lopez AD, Mathers CD, Ezzati M, Jamison DT, Murray CJ. Global and regional burden of disease and risk factors, 2001: systematic analysis of population health data. Lancet 2006; 367: 17471757.

2. Giovannucci E, Harlan DM, Archer MC, Bergenstal RM, Gapstur SM, Habel LA, et al. Diabetes and Cancer. A consensus report. Diabetes Care 2010 Jul; 33(7): 1674-1685.

3. Cancer Registry Report [Internet]. National Institute of Cancer Research and Hospital 2005-2007 [cited 2013 March 29]. Available from: http://www. ban.searo.who.int/LinkFiles/Publication_ Cancer_ registry_report.pdf

4. Grote VA, Becker S, Kaaks R. Diabetes mellitus type 2 - an independent risk factor for cancer? Exp Clin Endocrinol Diabetes 2010; 118: 4-8.

5. Vigneri P, Frasca F, Sciacca L, Pandini G, Vigneri R. Diabetes and cancer. Endocr Relat Cancer 2009; 16: 1103-1123.

6. Talukder MH, Jabeen S, Islam MJ, Hussain SMA. Distribution of Cancer Patients at National Institute of Cancer Research and Hospital in 2006. Bangladesh Medical Journal. 2008; 37(1): 2-5.

7. Markman M. Common complications and emergencies associated with cancer and its therapy. Cleve Clin J Med 61: 105-114, 1994.

8. Currie CJ, Poole CD., Jones SJ, Gale EAM, Johnson JA, Morgan CL. Mortality After Incident Cancer in People With and Without Type 2 Diabetes. Diabetes Care 2012 Feb; 35(2): 299-304.

9. Barone BB, Yeh HC, Snyder CF, Peairs KS, Stein KB, Derr RL, Wolff AC, Brancati FL. Long-term allcause mortality in cancer patients with preexisting diabetes mellitus: a systematic review and metaanalysis. JAMA 2008; 300: 2754-2764.

10. Lipscombe LL, Goodwin PJ, Zinman B, McLaughlin JR, Hux JE. The impact of diabetes on survival following breast cancer. Breast Cancer Res Treat 2008; 109: 389-395. 